\title{
SPOTTED: COMUNIDADES DE NAMORO NO FACEBOOK
}

\section{SPOTTED: DATING COMMUNITIES ON FACEBOOK}

\section{RODRIGO ESTEVES DE LIMA-LOPES}

DOUTOR EM LINGUÍSTICA APLICADA PELA UNICAMP

DOCENTE DO PÓS-GRADUACÃO EM LINGUÍSTICA APLICADA DA UNICAMP

PESQUISA FINANCIADA PELA FUNDAÇ̃̃O DE AMPARO À PESQUISA DO ESTADO DE SÃO PAULO (FAPESP) PROCESSO № 2016/11230-5.

E-MAIL: RLL307@UNICAMP.BR

ORCID ID: HTTP://ORCID.ORG/0000-0003-3681-1553

\section{RESUMO}

Este artigo tem por objetivo discutir os processos de interação em comunidades Spotted no Facebook. Tais comunidades têm por objetivo promover a conexão entre indivíduos à moda de um sítio ou aplicativo de namoro (online dating), utilizando, todavia, recursos de uma mídia social aberta. A análise aqui realizada se baseou na Linguística SistêmicoFuncional (HALLIDAY, 1978), na Ciência das Redes (BARABÁSI, 2002; SCOTT, 2013; WATTS, 2004) e na Comunicação Mediada por Computador (HERRING, 1996) de forma a lançar um olhar qualitativo e quantitativo sobre tais comunidades. A coleta de dados contou com ferramentas de raspagem de dados automatizados, sendo o processamento realizado por meio de softwares como Gephi. Foram estudadas as ligações de tais comunidades no Facebook, de forma a compreender como suas conexões de rede representam suas práticas sociais online e off-line. Procurouse também compreender qual a estrutura básica de suas postagens, de forma realizar um levantamento dos modos de linguagem (KRESS, 2010) utilizados. Os resultados refletem os processos de socialização e interação, entre eles estão a identificação dos possíveis parceiros por estratégias visuais e discursivas. Este sistema de busca de parceiros nas mídias sociais reflete, em sua identidade de rede, as relações sociais intra e extramuros dos grupos sociais nelas envolvidas e representadas.

PALAVRAS-CHAVE: Namoro online. Facebook. Contexto Brasileiro. Linguística-Funcional. Ciência das Redes. 


\section{ABSTRACT}

This article aims to discuss the interaction processes in Spotted Communities on Facebook. Such communities aim to foster the connection between individuals in the fashion of an online dating site or application by using open social media resources. The analysis performed here was based on Systemic Functional Linguistics (HALLIDAY, 1978), Network Science (BARABÁSI, 2002; SCOTT, 2013; WATTS, 2004) and Computer Mediated Communication (HERRING, 1996) as it takes a qualitative and quantitative approaches to such communities. Data collection included automated data scraping tools, and processing was performed using software such as Gephi. The links of such communities on Facebook were studied in order to understand how their network connections represent their online and offline social practices. We also sought to understand the basic structure of their posts, so as to conduct a survey of the language modes (KRESS, 2010) were used. The results reflect the processes of socialization and interaction, among them are the identification of possible partners by visual and discursive strategies. This system of searching for partners on social media reflects, in its network identity, the social relations inside and outside the social groups present and represented in such communities.

KEYWORDS: Online dating. Facebook. Brazilian Context. Systemic-Functional Grammar. Network Analysis.

\section{DISCUSSÕES PRELIMINARES}

Este artigo tem por objetivo discutir sobre o fenômeno das comunidades denominadas Spotted no Facebook de forma a compreender como se dá o processo de interação, a estrutura de suas postagens e o seu lugar dentro da rede de significações por ela representadas. Tais comunidades têm por objetivo servir como um site ou aplicativo de namoro online (online dating) - cuja função principal é conectar indivíduos que procuram por romance. Esta pesquisa se apoia em três abordagens: a Linguística Sistêmico-Funcional (doravante LSF), a Comunicação Mediada por Computador (doravante CMC) e a Ciência das Redes (doravante CR).

A primeira tem sua origem nos trabalhos de Halliday (1978) que parte dos estudos do antropólogo Malinowski de forma a construir uma abordagem à linguagem profundamente relacionada às noções de contexto e de escolha. Em seus trabalhos, Halliday (1978) observa 
que o contexto pode ser um elemento motivador dos processos comunicacionais, de maneira a possibilitar a construção de um sistema de significados baseados nas formas de expressão disponíveis para o falante.

Seu modelo de análise tem como elemento-chave a ideia de que os significados e seus diversos fraseados estão ancorados nas necessidades expressão e comunicação do falante. A LSF une forma e significado em uma conjuntura analítica que procura refletir sobre como escolhas socialmente significativas são realizadas. Nesse sentido, a gramática para Halliday (1978) é um construto paradigmático que permite ao usuário da língua realizar escolhas significativas, sendo que os constituintes estruturais se organizam como resultado da ação comunicativa.

Nesta abordagem a concepção de linguagem se constitui em planos de expressão de forma a considerar o significado como uma função, nos quais os textos refletem escolhas de acordo com dois níveis de contexto, o de cultura e o de situação. O primeiro estaria relacionado aos padrões sociais de instanciação de nossos significados, difuso e responsável pela estruturação da linguagem de forma a alcançar objetivos culturalmente apropriados (EGGINS, 1994). Seria, assim, correto afirmar que o reconhecimento de um texto como tal parte de nossa percepção desse Contexto de Cultura. No universo da Linguística-Funcional, é comum a percepção desse nível de contexto com o da instanciação dos gêneros (MARTIN, 2016).

O Contexto de Situação (ou Registro), por seu turno, é relativo ao momento de realização do texto. De acordo com ledema (2003), Halliday cria um sistema tridimensional que não se baseia apenas em um conjunto de regras formalistas, as quais podem ser refinadas. Essa tridimensionalidade se manifestaria pelas três variáveis de registro, responsáveis pela configuração das escolhas.

Dentro desse universo teórico, o Registro tem a função de materializar os textos por meio das escolhas léxico-gramaticais na esfera da ação de linguagem, ao passo que o Contexto de Cultura, estaria relacionado aos processos sociais (VIAN JR; LIMA-LOPES, 2005). Tal construto dá ao Registro um papel fundamental para materialização da cultura, sendo também responsável por imprimir os elementos determinantes da situação de instanciação.

Dessa forma, o Registro funciona como uma via dupla de interligação entre aquilo que falamos e seu efeito em termos sociais, sendo que tanto a linguagem seria condicionada pelo contexto, mas 
ele também o seria por ela. Isso tem implicações importantes para a construção do significado, sendo motivado pelo contexto (KRESS, 1993; HALLIDAY; HASAN, 1991).

A Comunicação Mediada por Computador pode ser definida como os processos de interação humana utilizando o computador conectado em rede (HERRING, 2001). Tais redes são encaradas como meios distintos da fala e da escrita, com efeitos próprios e específicos nos processos interacionais, discursivos e gramaticais. Inicialmente atrelada ao uso de computadores, tal área de pesquisa acabou por ampliar seus campos de atuação, abrangendo tais como dispositivos locativos e protocolos de Instant Message (doravente IM), uma vez que ela se desenvolve de forma paralela às tecnologias de rede (HERRING, 2001).

Para Herring (2001), há uma crença, sustentada tanto por acadêmicos como pelo senso comum, de que a linguagem mediada por dispositivos digitais é mais anárquica, menos organizada, menos correta e menos coerente do que a chamada linguagem padrão. Nesse sentido, vê-se um preconceito muito similar ao sofrido pela linguagem oral antes da Análise da Conversação discutir as regras interacionais específicas da fala. Assim, a CMC possui algumas características específicas; entre elas está a adaptabilidade dos participantes. Em meios sincrônicos, por exemplo, sofre-se uma pressão cognitiva comparável a fala face a face: respostas devem ser rápidas, dadas em um curto espaço de tempo e organizadas de forma a cumprir seu propósito de comunicação imediato. Já interações assíncronas podem ser mais elaboradas, uma vez que os participantes têm um tempo maior para elaboração da resposta. Afora questões técnicas, comunidades tendem a criar culturas específicas de comunicação, o que torna a análise de tomada de turnos, especialmente complexa.

Herring (2013) analisa a manutenção do piso conversacional em três grupos de discussão acadêmicos; seu objetivo principal é observar se há diferenças nas estratégias discursivas entre indivíduos de diferentes gêneros. Entre as questões interacionais típicas da CMC, observa-se que a frequente entrada e saída de indivíduos da interação permite uma constante troca de turnos. Diferentemente das interações face a face, a impossibilidade de interrupção permite que os participantes postem seus turnos, independente de a palavra ser ou não dada. Ou seja, participar ou não de uma interação assim como iniciar um novo tópico passa a ser uma algo possível para qualquer indivíduo, desde que participante do grupo. 
Herring (2013) mostra que os participantes masculinos tendem a iniciar um maior número de tópicos e discordâncias, enquanto as mulheres são responsáveis por um número maior de tópicos de concordância. Os homens tendem a postar mensagens mais longas e ter seus tópicos respondidos com maior frequência que as mulheres, havendo, ainda, um grande número de discussões paralelas em cada tópico. Tais resultados são importantes por demonstrarem que os suportes digitais influenciam interação, não podendo ser tratados com neutralidade. Ao influenciarem no processo comunicacional, eles ajudam a construir padrões linguísticos e normas interacionais próprias. Ambos estariam relacionados às possibilidades e limitações destes sistemas que parecem, em um primeiro momento, moldar a linguagem. Efetivamente, o que acontece é um processo de construção de padrões e normas que satisfazem às necessidades comunicacionais no contexto em que se inserem. Por fim, Lima-Lopes e Pimenta (2017) contribuem à medida que realizam uma conexão entre a CMC e a LSF para a compreensão dos processos ideológicos na linguagem desses meios.

Já a CR é uma abordagem interdisciplinar que reflete sobre a constituição de redes como um fenômeno, estabelecendo modelos de compreensão preditivos. De forma geral, presume-se que tais redes sejam formadas tanto por motivações aleatórias, como estabelecidas por relações motivadas pelo ambiente social (BARABÁSI, 2002; SCOTT, 2013; WATTS, 2004). Watts (2004) reflete sobre o poder de caracterização das redes. Para o autor, nossas conexões são uma forma de expressão de nossa identidade, representando as características de um indivíduo. Ou seja, a quem nos conectamos, e a qualidade de tais conexões (quão expressivas elas são e qual papel excercemos junto à elas), não apenas leva à realização de diferentes funções nos diversos ambientes de rede nos quais estamos conectados, como também leva cada um a assumir diferentes papéis em suas redes.

Há poucos estudos em nossa área que partem de tal abordagem, entre eles gostaria de destacar Lima-Lopes $(2017,2018)$ e Gabardo e LimaLopes (2018). Lima-Lopes (2017) reflete sobre as possíveis contribuições da Ciência das Redes para o estudo do contexto de situação em um grupo de WhatsApp. Seus resultados mostram que as métricas utilizadas para determinar a centralidade dos participantes também identificam os diversos papéis assumidos por eles. Em outras palavras, o autor observa que diferentes funções discursivas estão relacionadas à quantidade de interações que um usuário possui. Já em Lima-Lopes (2018), são discutidas 
questões de fundo em relação às ações de linguagem em mídias sociais: o autor parte da instabilidade dessas postagens para pensar nos limites teóricos da abordagem baseada em gêneros. Gabardo e Lima-Lopes (2018), por seu turno, discutem o sucesso de um coletivo de luta pelo direito das mulheres na Argentina. Seu estudo mostra como estratégias discursivas e representacionais em rede contribuem para formação de uma manifestação política em prol de pautas específicas.

Como colocam Zell e Moeller (2018), o crescimento das conexões em mídias sociais parece levar a um crescimento da autoestima, especialmente por elas proporcionarem a manutenção de relacionamentos e amizades, retomando conexões perdidas (ELLISON; STEINFIELD; LAMPE, 2007). Tal característica parece estar diretamente relacionada ao crescimento de participação em grupos de discussão e postagens, o que poderia afetar a percepção da própria plataforma midiática.

Uma questão relevante a ser observada é que a comunicação em mídias sociais pode estar motivada por experiências no mundo off-line. Como colocam Ross e colaboradores (2009), apesar de questões referentes à personalidade não serem determinantes na escolha de utilização de tais mídias, o uso por indivíduos com maior nível de desinibição parece ter uma relação positiva com a utilização da plataforma (CORREA; HINSLEY; DE ZÚÑIIGA, 2010). Outro ponto importante em sua utilização é a percepção do lugar social ocupado por um indivíduo em termos de seus relacionamentos amorosos. Há diferenças na forma como homens e mulheres tratam a publicização de seu status de relacionamento: elas tendem declará-lo publicamente, ao passo que homens não (FOX; WARBER, 2013). A prática de omissão do status pelos homens pode ser avaliada negativamente (OROSZ et al., 2015) pela parceira no caso de homens que se encontram em um relacionamento estável, uma vez que isso pode significar a busca de parceiras paralelas (PAPP; DANIELEWICZ; CAYEMBERG, 2012).

Neste artigo, gostaria de definir online-dating como a busca ou iniciação de relacionamentos na esfera online. Algo que, certamente, deve pressupor práticas como a seleção de parceiros em potencial e a interação mediada pelo computador como forma de cortejo que antecede o início de um relacionamento off-line, havendo, comumente, uma progressão entre canais de interação até que haja o contato face a face (SPRECHER, 2009).

De maneira geral, a utilização de Mídias Sociais para a busca de 
parceiros, estáveis ou não, parece ser uma tendência. De acordo com Smith e Duggan (2013), algo em torno de 59\% dos usuários de internet adultos dos EUA considera online-dating como uma maneira eficiente de se conhecerem novas pessoas, sendo que, pelo menos, 53\% destes mesmos usuários julgam que tais práticas os ajudam a encontrar um melhor partido. Seus resultados ainda mostram que algo em torno de $42 \%$ conhece alguma pessoa que admite ter utilizado tais serviços e 29\% relatam ter em seus círculos alguém que encontrou um parceiro estável por meio deles. Um traço comum a tais pessoas é que elas buscam pessoas que dividam interesses ou a mesma origem. Tais fatos parecem corroborar o trabalho de Sprecher (2009), cuja pesquisa mostrou que algo em torno de $6 \%$ dos atuais casamentos nos EUA se iniciou a partir de interações na rede.

Segundo a autora (SPRECHER, 2009), apesar da ideia de onlinedating ainda ter certa homogeneidade para público leigo, há algumas diferenças que precisam ser observadas. Isso se dá especialmente se pensarmos na natureza dos loci digitais utilizados, uma vez que o encontro pode ser motivado por plataformas específicas para a procura de parceiros ou mesmo ocasionalmente. No primeiro, são utilizados sistemas próprios e que possuem algoritmos específicos (tais comoTinder) e outros, tais como fóruns, comunidades de jogos ou grupos de notícia, nos quais o encontro pode ocorrer "sem querer". Como colocam tanto Smith e Duggan (2013) como Sprecher (2009), outro fator importante em tais contextos é a possibilidade de busca de informações sobre possíveis parceiros antes mesmo do primeiro contato online acontecer.

Rochadiat e colaboradores (2018) estudam práticas de cortejo online por grupos de jovens islâmicos, sendo que o estudo tem como foco observar qual a visão que as mulheres muçulmanas possuem desse cortejo online. Seus resultados mostram que, ao mesmo tempo em que tais sítios possibilitam uma aproximação entre pessoas de sexos opostos, burlando as estritas regras de relacionamento da comunidade e permitindo o conhecimento mútuo entre parceiros, ela também causa preocupação com a autoimagem dessas mulheres. Alguns resultados são similares aos de Arora e Scheiber (2017), que estudam o Facebook como plataforma de relacionamento por jovens em países emergentes. As autoras não apenas observam que tal plataforma se caracteriza por um lugar de experimentação sexual e busca de parceiros, mas também levantam algumas questões importantes como a exposição feminina, especialmente no que tange ao pornô de vingança. 
Dado o papel que as mídias sociais têm desempenhado em nossa sociedade, é importante compreender como ela influencia nos processos de socialização de jovens adultos. Apesar de Arora e Scheiber (2017) estudarem o contexto brasileiro, ainda faltam reflexões sobre como tais processos de socialização ocorrem em comunidades específicas para o online-dating.

\section{METODOLOGIA}

Esta pesquisa contou com uma abordagem mista à análise de dados, que foram analisados a partir de critérios quantitativos e qualitativos.

As quatro comunidades estudadas nesta pesquisa foram escolhidas a partir de dois critérios: 1 ) número de participantes no momento da coleta de dados e 2) atividades recentes nas últimas 24 horas antes da pesquisa. Assim, foram escolhidas as quatro comunidades com maior número de participantes que tivessem atividades de postagem nas últimas 24 horas antes da pesquisa. No caso de haver mais de uma comunidade com tal atividade, escolheu-se a que tivesse o maior número de postagens de forma a estudar-se aquelas com interação mais frequente dentro da mídia social em que se situam. A coleta de dados ocorreu em 30 de abril de 2018.

A coleta de dados ocorreu de forma automática, com a utilização do Netvizz ${ }^{1}$ (ROGERS, [s.d.]), um aplicativo online capaz de coletar dados de páginas, grupos e perfis disponíveis no Facebook em modo público. Entre os dados coletados, estão:

- Conjunto de postagens e seus textos

- Conexões em rede entre as páginas dentro do contexto do Facebook

Por questões referentes a capacidade de processamento dos computadores utilizados nesta pesquisa, foram coletados os 100 posts mais recentes de cada página estudada, de forma a proporcionar uma amostra equânime, valendo-se da descrição paramétrica da amostra (ANOVA).

A análise qualitativa das postagens buscou realizar uma análise:

1) dos processos utilizados na construção da imagem do objeto de desejo;

1 Infelizmente, após dezembro de 2019, o Facebook fechou acesso gratuito aos seus dados de pesquisa, por razões referentes ao chamado "Escândalo Cambridge Analytica" (SCHNEBLE; ELGER; SHAW, 2018). 
2) das relações entre texto e imagem, quando estes estão presentes; e

3) a estrutura das postagens, compreendendo como as variáveis de registro se constituem.

A análise quantitativa buscou observar:

1) a relação entre a página pesquisada e outras páginas dentro da plataforma;

2) a natureza dessas conexões (que tipo de páginas e a natureza das relações); e

3) a descrição paramétrica da amostra, sendo aplicado o teste ANOVA.

ANOVA é um teste paramétrico cujo objetivo principal é analisar a variância entre amostras compostas por mais de dois grupos. Seu objetivo é comparar médias de forma a observar se tais grupos possuem médias diferentes ou iguais (BREZINA, 2018). No caso específico deste estudo, comparam-se as médias de produção de conteúdo pelos grupos estudados, sendo que a hipótese $\mathrm{H}_{0}$ seria igual à não diferença entre as médias, o que significaria que tal variância seria normal nesse tipo de grupo, ao passo que a $\mathrm{H}_{1}$ seria equivalente à diferença entre essas médias, dando a cada grupo uma variância significativa em termos de atividade. Em outras palavras, $\mathrm{H}_{1}$ implicaria que tais grupos são diferentes em termos dos eventos comunicativos que geram.

Os anúncios são diferentes dos sítios especializados em namoro virtual. Não há pessoas descrevendo suas características físicas ou emocionais em busca de um parceiro idealizado, mas sim indivíduos que identificaram - conforme uma das possíveis traduções de spotted - um parceiro possível e, utilizando a página como um mural, deixam recados buscando ser contatados por ela(e). Tais comunidades possuem postagens anônimas e mediadas pelo administrador, e somente o nome do alvo da afeição, ou sua imagem, é identificada; o que faz com que o/a pretendente seja anônima(o) e o/a pretendida(o) identificável. Em boa parte, tal prática permite que declarações de interesse sejam feitas de forma a preservar a face daquele que se expõe ao se declarar afeiçoado por outrem. Tais páginas costumam ser específicas de um domínio social, e povoadas por indivíduos que dividem o mesmo contexto fora do Facebook. Isso ocorre porque, em todos os casos, elas são dedicadas 
a comunidades como escolas, universidades e, até mesmo, a linhas de transporte coletivo. Tal característica funciona como um geo-delimitador, selecionando os participantes a partir de um critério com origem no mundo não virtual.

No caso desta pesquisa, são estudados grupos ligados a duas universidades públicas - uma do interior de São Paulo e outra do interior de Minas Gerais - uma particular, situada na capital paulista, e uma ligada ao sistema de transportes metroviário paulistano. A escolha é fruto da interação que elas apresentam: foram escolhidas as comunidades com maior interação no momento da coleta. A comparação entre as comunidades busca observar o que é comum à prática de busca de parceiros em tais comunidades e o que pode se apresentar de característico de cada uma.

\section{INTERAÇÃO NAS COMUNIDADES: MÉTRICAS E REDE DE CONEXÕES}

A tabela 1 traz algumas métricas das comunidades Spotted pesquisadas neste trabalho, sendo que, de forma a parametrizar o processo de compreensão da interação, a investigação levou em conta um número fixo de postagens (100) para cada comunidade. As duas comunidades com menor número de postagens/dia são a Faculdade Particular Paulistana (doravante PaP) que possui uma média de 2,38, ao passo que Metrô Paulistano (doravante MP) possui números em torno de 1,12. Por outro lado, a comunidade ligada a Universidade Pública Minas Gerais (doravante PG) possui uma média de 5,8 postagens, ao passo que a comunidade que representa a Universidade Pública Paulista (doravante PuP), possui números bastante acima da média, com 50 postagens iniciadas a cada dia.

Tabela 1: Interações no corpus de estudo

\begin{tabular}{|cccc|}
\hline \multicolumn{2}{|c|}{ Particular Paulistana (PaP) } & \multicolumn{2}{c|}{ Pública M. Gerais (PG) } \\
\hline Posts & 100 & Posts & 100 \\
Reações & 1369 & Reações & 820 \\
Comentários & 1600 & Comentários & 339 \\
Compartilhamento & 1 & Compartilhamento & 1 \\
Número Dias & 42 & Número Dias & 17 \\
Posts/Dia & 2,38 & Posts/Dia & 5,8 \\
Engajamento & 2970 & Engajamento & 1160 \\
Participantes & 2102 & Participantes & 15501 \\
\hline
\end{tabular}




\begin{tabular}{|cccc|}
\hline \multicolumn{2}{|c|}{ Pública Paulista (PuP) } & \multicolumn{2}{c|}{ Metrô Paulistano (MP) } \\
\hline Posts & 100 & Posts & 100 \\
Reações & 528 & Reações & 653 \\
Comentários & 422 & Comentários & 92 \\
Compartilhamento & 2 & Compartilhamento & 10 \\
Número Dias & 2 & Número Dias & 89 \\
Posts/Dia & 50 & Posts/Dia & 1,12 \\
Engajamento & 952 & Engajamento & 755 \\
Participantes & 16000 & Participantes & 22244 \\
\hline
\end{tabular}

Fonte: Dados de Pesquisa

Tabela2:Análise de variância $p=2,98728 \mathrm{E}-05$ (0.004203)

\begin{tabular}{|l|c|c|c|}
\hline \multicolumn{1}{|c|}{ Variáveis } & Soma & Média & Variância \\
\hline Reações & 3370 & 842,5 & 137509,667 \\
\hline Comentários & 2453 & 613,25 & 452388,917 \\
\hline $\begin{array}{l}\text { Compartilha- } \\
\text { mento }\end{array}$ & 14 & 3,5 & 19 \\
\hline Número Dias & 150 & 37,5 & 1451 \\
\hline Posts/Dia & 59,3 & 14,825 & 553,8121 \\
\hline Engajamento & 5837 & 1459,25 & 1041728,92 \\
\hline Participantes & 55847 & 13961,75 & 71924362,9 \\
\hline
\end{tabular}

Fonte: Dados de Pesquisa

Em termos de comentários, PaP possui uma média de 16 comentários por postagem - sendo a mais profícua nesse quesito - seguida pela PuP, que apresenta a segunda (média de 4,22), por PG, (com 3,39), sendo a que possui menos comentários é, novamente, por MP (apenas 0,92). PaP é a comunidade com maior número de reações (uma média de 13,69 por postagem), seguida por PG (com 82 em média) e por MP (com $65,3)$. A última métrica a ser observada é o engajamento, calculado por meio da soma dos comentários, reações e compartilhamentos realizados em cada grupo. Os resultados colocam PaP como a comunidade mais engajada (com 2970), seguida por PG (com 1160). As duas com menor engajamento seriam a PuP (952) e do MP (755). 
A tabela 2 traz os resultados a partir da análise de variância, sendo que o resultado do teste ANOVA mostrou-se significativo em termos da diferença de distribuição entre as amostras de cada grupo. De maneira geral, os números trazidos pelas tabelas 1 e 2 parecem levar a uma quebra de minhas expectativas iniciais. Apesar de MP ser a maior entre as comunidades pesquisadas, sua média é a mais baixa, ao passo que $\mathrm{PaP}, \mathrm{a}$ comunidade com menos participantes é a mais engajada e possui maior número de comentários. Minhas expectativas também se frustraram em termos da quantidade de postagens/dia, uma vez que imaginava que os grupos mais profícuos em termos de engajamento e comentários também seriam os com maior quantidade de postagens.

Primeiramente, é possível observar (tabelas 1 e 2), que a relação entre o engajamento, número de postagens e de participantes precisa ser analisada com alguma cautela. Isso porque, apesar de PaP ser a menor das comunidades, ela é a mais engajada, com maior número de reações e comentários. Tais resultados também podem significar que comunidades menores podem ser mais uníssonas, algo que pode ser motivado pela amplitude de seu elemento geo-delimitador. Uma possível explicação é o fato de PaP ser referente a uma instituição de ensino, com pouco mais de 2500 alunos ativos, ao passo que PG possui algo em torno de 11752 alunos, PuP com 35666 alunos, e MP transporta 4,5 milhões de passageiros dia. Em outras palavras PaP agrega quase a totalidade de participantes da comunidade não-virtual por ela representada.

Um dos resultados que mais surpreendeu nesta análise é que PaP não possui conexões, ao passo que MP se relaciona com apenas uma página, fatos que podem ser motivados pela abrangência de ambas. $\mathrm{PaP}$ representa uma faculdade com pouco mais de 2500 alunos, sendo que, como já discutido, parte significativa deles está inscrita na comunidade. Ao mesmo tempo, seu tamanho - todos os setores estão distribuídos em dois andares de um mesmo prédio - faz com que não haja pulverização de seus institutos ou setores administrativos, conexões deveras comuns em outros grupos. Já MP pode ter em sua grande abrangência geográfica a justificativa, uma vez que o uso do sistema de transporte paulistano pode não ser o suficiente para construção de uma identidade. Em outras palavras, tanto a proximidade e representatividade, quanto a pulverização pelo tamanho podem ser explicações para este fenômeno.

$\mathrm{PuP}$, por seu turno, possui conexões representadas pela figura 1. Como é possível observar, ela se relaciona com páginas de diversas categorias, quase 25 no total. Na parte central da figura, PuP se relaciona 
diretamente com uma série de páginas relacionadas a seu cotidiano acadêmico (com o sufixo PuP), entre elas estão comunidades responsáveis por oferecer suporte à pessoas com diferentes questões acadêmicas e pessoais (rosa), repúblicas, além de páginas de suporte relacionadas a outras instituições de ensino superior (amarelo escuro). Na parte inferior direita, podem ser observados diversos nós referentes a atléticas (azul claro), eventos (vede escuro) e grupos musicais (marrom). Na parte superior central, há a conexão com diversas comunidades Spotted (verde claro) de outras universidades - as quais também estão na parte central inferior -, além de diversas organizações não governamentais (lilás). Na parte inferior esquerda, por sua vez, há a concentração de empresas (laranja claro) e páginas pessoais.

Figura 1: Conexões de PuP

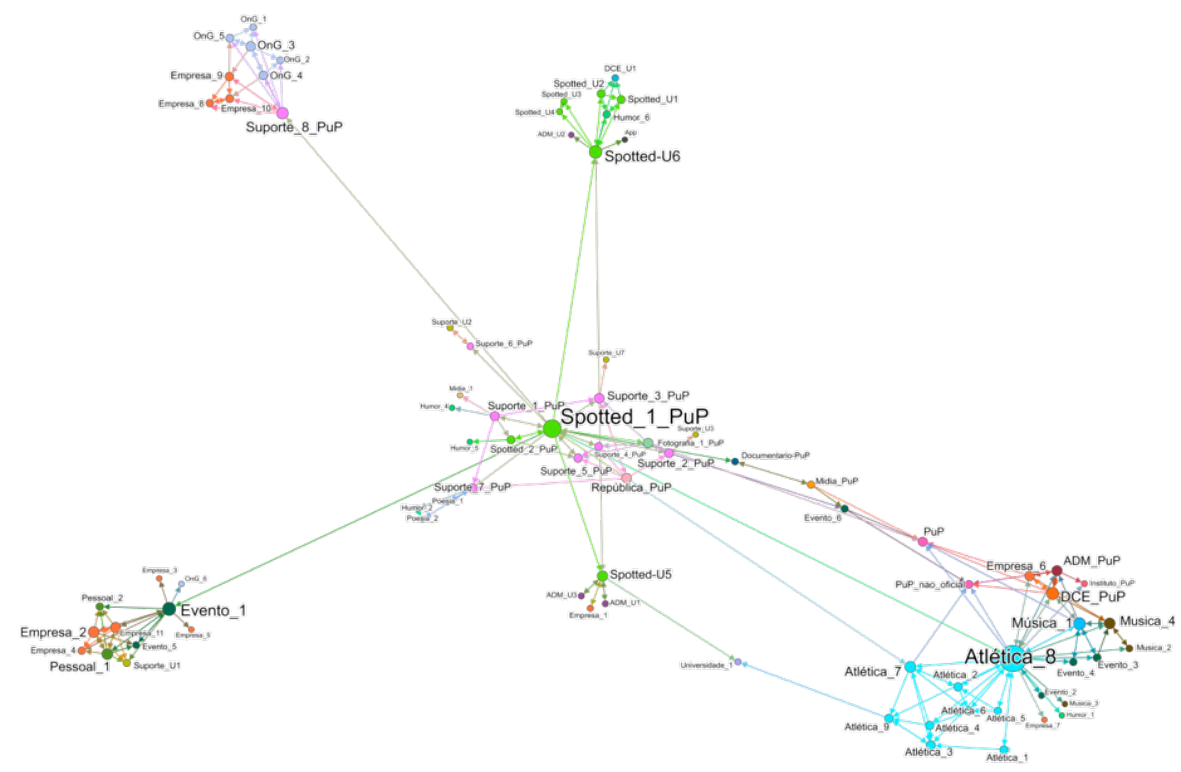

De forma geral, podemos observar que a rede expressa na figura 1, a rede de páginas a que PuP se conecta possui diversos hubs importantes. Estes são responsáveis por ligar uma série de páginas da mesma categoria, como seriam as atléticas e as Ongs, que parecem formar subredes de interação. Isso ocorre porque PuP parece se relacionar a elas por meio das ações de seus próprios usuários. Tomemos por exemplo o grupo 
constituído pelas atléticas, músicas e eventos: por ser um Spotted oficial de toda a universidade, cada vez que uma das diversas atléticas realiza um evento, a página referente a atlética em questão, os perfis das pessoas participantes, assim como o evento em si, são marcados em diversas postagens. Como resultado, isso faz com que Spotted acrescente algumas dessas páginas em sua lista de curtidas. O mesmo pode ser dito em relação as empresas que se relacionam ao "Evento_1", tais empresas participam do evento ou o promovem, sendo assim marcadas e curtidas nas ações de paquera. Algumas Ongs, por seu turno, parecem estar relacionadas às páginas de suporte mantidas por alunos, algo que pode ser um resultado da natureza dessas organizações, que também oferecem ajuda a indivíduos com problemas discutidos nessas comunidades. Aquelas que não se relacionam a tais atividades parecem ter sido acrescentadas pelo seu caráter político.

Figura 2: Rede Conexões de PG

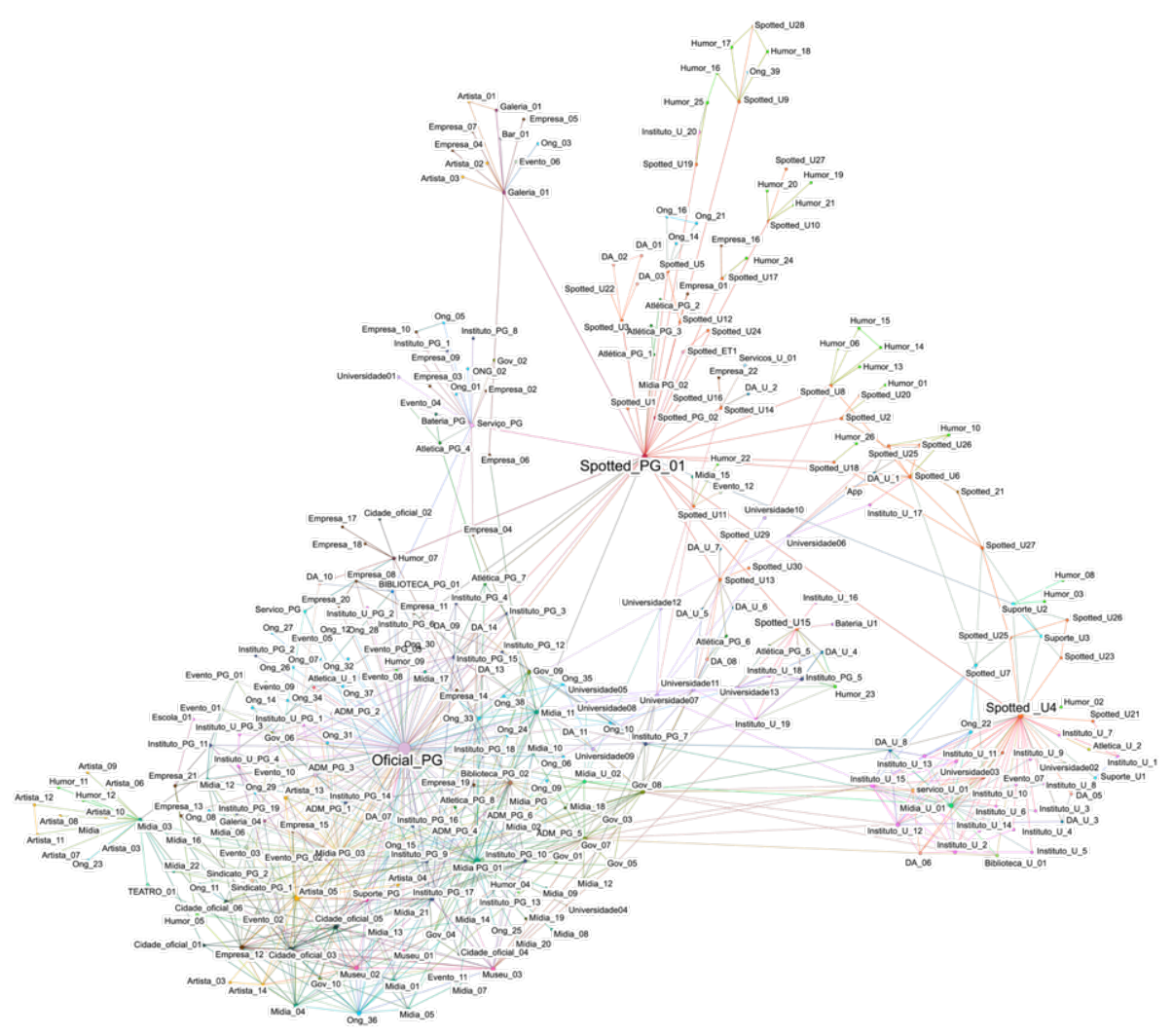


A figura 2 traz as conexões de PG. Como é possível observar, ela é uma rede muito maior e com uma configuração diferente da representada na figura 1. Algo a ser levado em conta é que Spotted_PG_01, comunidade pesquisada neste trabalho, não é a única página com tal função em PG, algo significativo por demonstrar que tal forma de conexão pode ser uma prática comum aos alunos dos diferentes institutos. Assim como PuP, PG se conecta a ONGs (azul turquesa), Spotteds (laranja), outras universidades (lilás), empresas (marrom) e diretórios acadêmicos (laranja escuro). Diferenças em termos da natureza das conexões estão na presença de museus (rosa), institutos da universidade (magenta), institutos de outras universidades (também magenta), artistas (amarelo escuro), escolas (rosa claro), empresas midiáticas (verde escuro) e órgãos governamentais diversos (verde escuro). No total, são 45 tipos de páginas às quais $\mathrm{PG}$ se conecta, 20 a mais que PuP.

Isso mostra, primeiramente, que PG possui uma preocupação maior em construir uma rede de referências, algo que pode justificar seu engajamento ser maior do que PuP. Também deve ser levada em conta é a pulverização vista na figura 2. Nela há três nós principais, a própria Spotted_PG_01, a página oficial da universidade (Oficial_PG) e o Spotted de outra universidade (Spotted_U4), além de dois hubs menos centrais, serviço_PG e galeria_01. Spotted_PG_01 se conecta diretamente a Ongs, outras comunidades Spotted, páginas de humor e de serviços acadêmicos de sua própria universidade, além de eventos diversos. Já Oficial_PG garante a conexão com diversos institutos da universidade e suas mídias, além de setores administrativos, escolas, páginas oficiais de cidade, além de outras universidades, ONGs e eventos acadêmicos. Spotted_U4, por seu turno, faz uma ponte com seus institutos e diretórios acadêmicos (não pertencentes a PG), além de atléticas e ONGs.

\section{A ESTRUTURA DAS POSTAGENS E SUAS RELAÇÕES FUNCIONAIS}

As comunidades se caracterizam por construir um sistema funcional no qual o contexto imediato de realização da linguagem é uma característica determinante. Em termos gerais, a interpretação de tais postagens é claramente dependente da participação da vida cotidiana do recorte que elas apresentam.

Como mostram resultados, as postagens parecem seguir quatro tipos de padrão. O primeiro está relacionado à publicização da imagem da pessoa objeto de afeto seguida de uma descrição pormenorizada de sua roupa e tipologia física, de forma a destaca-lo em relação aos demais 
indivíduos que podem estar presentes em uma mesma fotografia (figura 3-A). O segundo também representa o objeto de afeto, todavia, a foto é marcada com linhas que identificam a pessoa, isolando-a das demais pessoas (figura 4-B). No terceiro padrão, há a descrição do contexto e da pessoa a que se pretende conhecer, sem a utilização de quaisquer imagens (figura 3-b). Finalmente, o quarto padrão traz um texto descrevendo o contexto, agora ilustrado por uma imagem de caráter romântico sem relação direta com a pessoa ou a situação. As figuras 3 e 4, que representam as postagens, estão posicionadas mais a frente, por questões de espaço.

Se há um elemento comum entre todas as comunidades é a promessa da publicação anônima. Nos grupos estudados, pude observar que são duas as formas que buscam garantir tal anonimato. Na primeira, comum a todas elas, há a possibilidade de envio de mensagem direta aos administradores (texto e imagem), que garantem que o nome do remetente não será divulgado. Na outra, comum apenas a PuP e PG, há a possibilidade do preenchimento de formulários específicos que ficam fora da plataforma de mídia social. Em PuP, tal formulário é hospedado em um domínio WWW e permite aos usuários escrever sua mensagem, sendo que o envio de imagens é condicionado a um login com a senha de seu Facebook. Tal sítio de internet ainda permite que uma série de informações sejam acessadas, tais como uma lista de publicações e o contato daqueles que postaram e permitiram tal acesso. Já em PG, tratase de um formulário do sistema Google que não solicita identificação alguma, mas não permite o envio de imagens.

Algo importante a ser observado é que, em todas as comunidades, o envio de imagens parece possível apenas se o usuário comprometer parte de seu anonimato, depositando um voto de confiança no administrador da página. Isso pode ter um impacto importante na natureza das postagens, uma vez que tanto em PuP como em MP a postagem de imagens é algo raro. Algo que também parece chamar a atenção é o processo de indexação existente na maioria dessas páginas. Apesar de omitido de forma a preservar a identidade dos participantes dos Spotted estudados, PuP, MP e PG possuem um número indexador da postagem na parte superior, logo abaixo do nome da comunidade e tem por objetivo servir como referência no caso de reposta indireta - quando algum participante envia uma resposta utilizando os administradores como ponte —, ou quando uma referência à postagem é realizada na comunidade - o que pode ocorrer ou em outra postagem 
ou nos comentários.

A linguagem é organizada de forma a possibilitar elementos de identificação de parceiros possíveis dentro do ambiente determinado geograficamente pela comunidade. Há a construção de um processo descritivo/narrativo que busca associar o maior número possível de elementos e características que possibilitem a individualização e, em especial, o auto reconhecimento. Quando apenas a linguagem escrita está presente, tal configuração parece buscar uma narrativa extensa dos fatos que geraram o encontro, levando a presença de um texto mais rico em detalhes visuais traduzidos em modo verbal.

Ex. 1

- Eu preciso achar um moço que estava na linha vermelha hoje, por volta das 5:20h, provavelmente voltando do sp na rua, ele desceu no carrão estava no primeiro vagão, eu estava sentada no chão com meu amigo no meu colo e a gente trocou vários olhares e sorrisos, fiquei tão apaixonada que nem tive tempo de tirar foto, ele desceu e ficou olhando $p$ trás... Ele era meio loiro, estava com um tênis da Nike, uma calça bege e uma bolsinha de lado. Me ajudem a achar o amor da minha vidaaaaaa. moço se vc ler isso eu sou a menina de dread que tava no chão na sua frente e a gente trocou mt olhares apareçaaaaa. Se ajudar a gente tava no mesmo vagão que o cara que tava vomitando, vai que ajuda a lembrar kkkk

O exemplo 1 que traz a transcrição do texto presente na figura 3 (imagem B-MP), e demonstra algumas das estratégias comuns de uma postagem constituída apenas pelo texto. Ali é possível observar a localização temporal e espacial do encontro, este último por meio de uma particularidade (homem vomitando) e pela estação em que o menino desceu (Carrão). A identificação de elementos da vestimenta também é algo importante, especialmente por não haver uma relação do texto com à imagem. Algo que chama a atenção é o fato de a remetente tentar estabelecer uma imagem de si mesma, isso para que o possível alvo de seu afeto a reconheça e responda a postagem. Tal estratégia é única de MP e pode ser o resultado da grande transitoriedade de seus usuários: diferentemente de uma universidade, é quase impossível encontrar a mesma pessoa nos vagões do coletivo. Além disso, é notável que toda 
a sequência do encontro está presente em forma de caracterização do contexto geral.

Figura 3: Exemplos de postagem

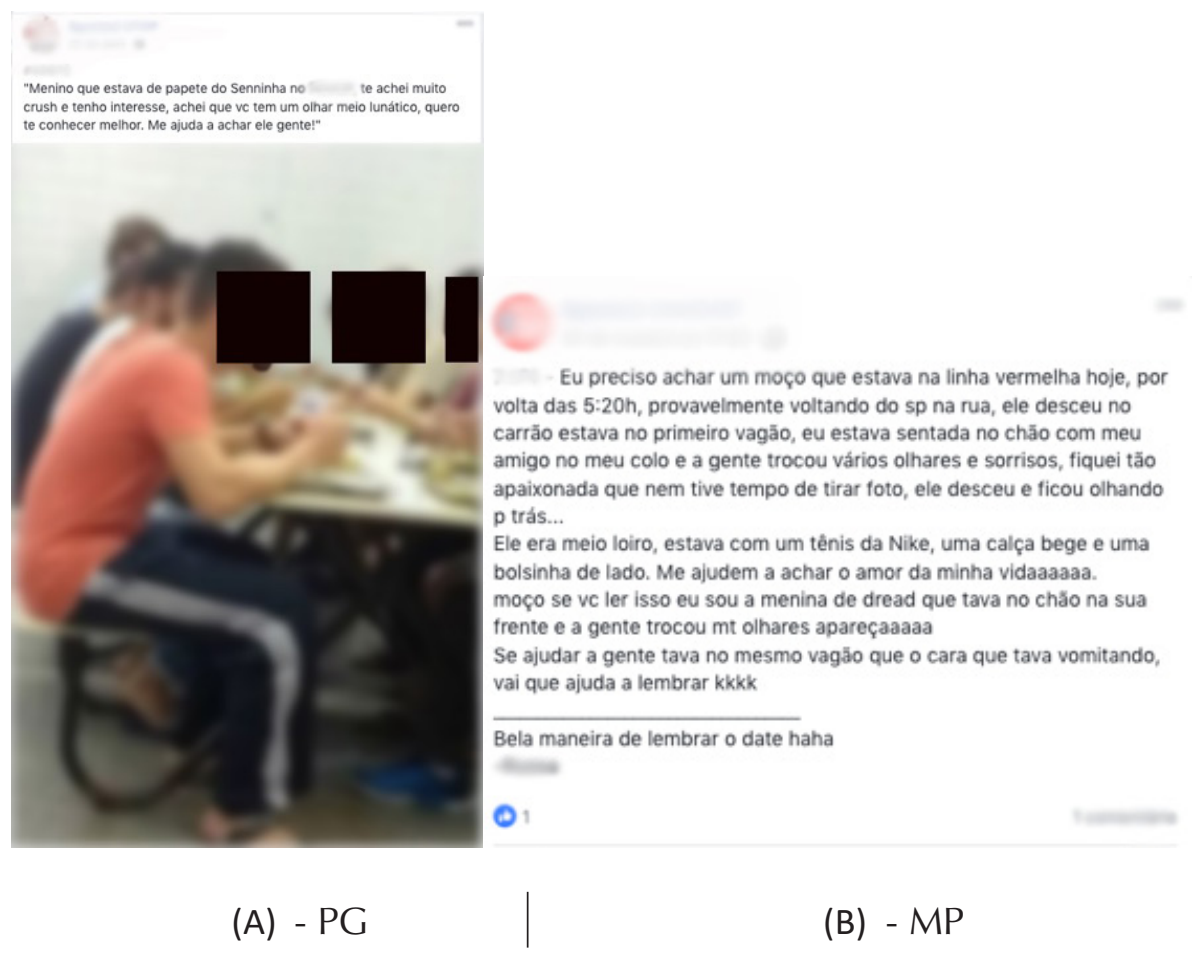

De certa forma, tal fato estaria relacionado à impossibilidade de vinculação de fotografias dado o contexto do transporte coletivo da cidade, em especial o grande fluxo de pessoas. Algo que o próprio texto da postagem parece mencionar. Já na figura 4 (C-PuP), isso ocorre devido a uma estratégia de identificação da pessoa-alvo: aqui ela é chamada pelo nome e inscrita no discurso de forma direta. Isso, todavia, não significa que a pessoa alvo de afeição responda a tal postagem, como é o caso.

Em alguns casos (figura 3-A e 4-A e B), são utilizados recursos visuais nas postagens. Sua função inicial pode ser a identificação do participante, seja pela ilustração de seus atributos físicos (figura 3-A) seja pela utilização de recursos externos a foto, como círculos ou setas destacando a pessoa-foco. Em outras situações, comuns em PuP, a 
imagem é utilizada com o objetivo de ilustrar sentimentos em relação à pessoa-foco, como é o caso da figura 4-A. Quando as imagens estão presentes, elas acabam por reduzir a necessidade desta narrativa, uma vez que a fotografia serve ao propósito de identificar tais traços. Vale ressaltar que tais imagens não são apresentadas de forma tratada, como foi o caso neste estudo: as pessoas são claramente identificáveis pelos traços do seu rosto e vestimenta.

Ex. 2

- "Menino que estava de papete do Senninha no XXXX, te achei muito crush e tenho interesse, achei que vc tem um olhar meio lunático, quero te conhecer melhor. Me ajuda a achar ele gente!"

Em termos gerais, a relação entre imagem e linguagem verbal ocorre com dois objetivos. O primeiro seria identificar o indivíduo de interesse quando há mais de uma pessoa ali representada. Neste caso, o sistema utilizado na associação entre o texto e a imagem é essencialmente metonímico, no qual algum elemento é escolhido como forma de representação do indivíduo. Como se observa na figura 3 (imagem APG), tal representação parece ser o resultado da relação entre alguma peça de vestimenta ou característica física; como é possível observar no exemplo 2, que traz o texto referente à figura 3 (imagem A-PG) e em que um estudante é identificado pelo seu calçado (papete do Senninha), pelo olhar e pela referência a um refeitório na universidade.

Ex. 3

- PEDIDO SUCINTO, GOSTEI "Queria saber quem é"

No segundo, como mostra a figura 4 (B-PaP), nem sempre a relação entre texto e imagem parece identificar características dos indivíduos na postagem. No exemplo 3, lugar no qual se transcreve o texto da figura 4 (B-PaP), é possível observar que o texto é uma simples inquisição pela identidade de uma garota, a relação com a imagem é uma referência catafórica representada pelo círculo. A relação se torna ainda menos estreita se for levada em conta a postagem presente na figura 4 (C-PuP), na qual vemos o texto transcrito no exemplo 4. Ali a imagem de uma rosa não tem relação referencial alguma com o texto, que expressa o 
sentimento de tristeza pela ausência de alguém. Como discutiremos mais a seguir, tal ilustração parece ter uma importância na tradução dos sentimentos ali presentes.

Ex. 4

— XXXXX Por quê você sumiu da XXXX? Sua falta é sentida.

Poucas vezes conversamos, e agora não te vejo mais aqui.

Você tem uma admiradora. Queria te conhecer melhor.

Figura 4: Exemplos de postagem - 2
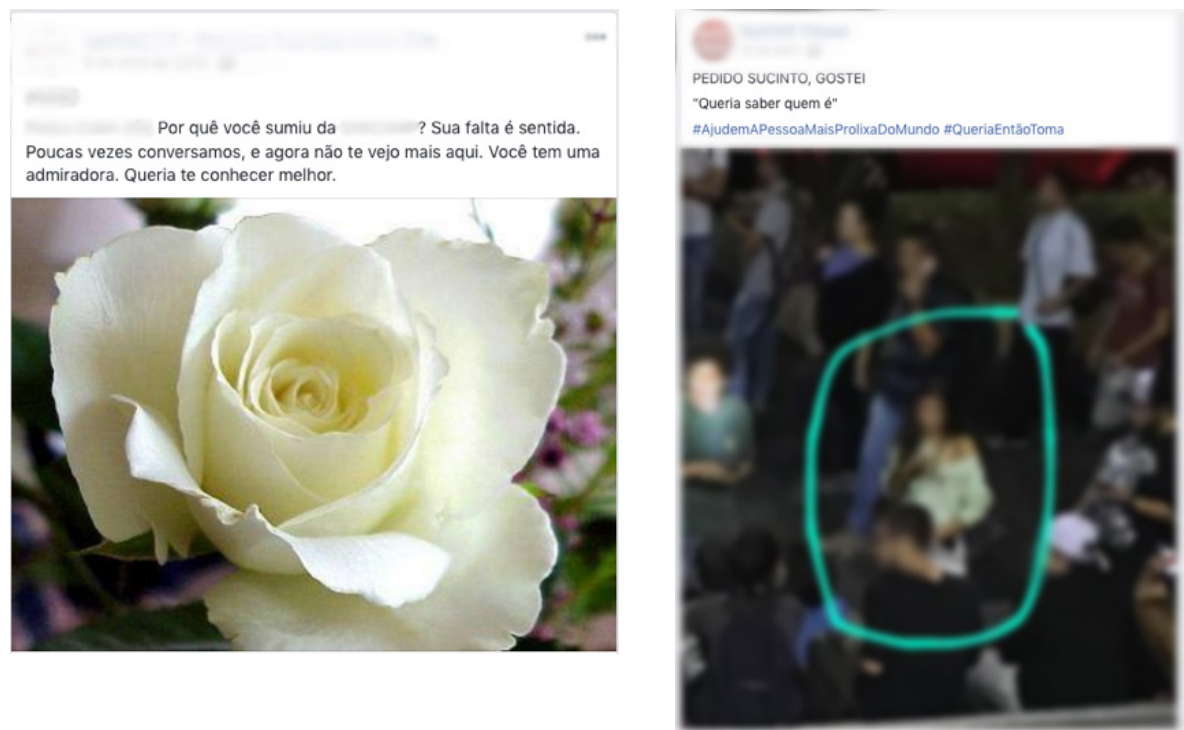

(A) - PuP

(B) $-\mathrm{PaP}$

você ta solteira? Uma menina da med teria chances?

$00 \% 3$

(C) - PuP 
Além das questões já colocadas, é importante trazer à baila que os processos de veiculação de imagens podem ser um resultado das políticas de anonimato explicadas anteriormente, fato que poderia estar diretamente relacionado à variável Relações estabelecidas entre os participantes. Isso pode ocorrer porque é demandado um nível de identificação para enviá-las - uma vez que, em última instância, o administrador terá conhecimento do responsável pelo envio -, podendo gerar relativo constrangimento. Uma das razões, para além da identificação do remetente no ambiente é o fato de tais anúncios possuírem, uma declaração de interesse por parte de seu autor. Isso pode ocorrer de forma indireta, como é o caso da figura 3 (B-MP), na qual a autora, ao construir uma narrativa do encontro, coloca-se como uma entidade feminina, ou da figura 4 (A-PuP), cujo tema central é a percepção de que um rapaz que parece não mais frequentar o ambiente universitário. Há a exposição do feminino que se coloca como figura interessada e iniciadora do processo de paquera, sendo que, como é o caso da figura 4 (C-PuP), assume-se também uma orientação sexual passível de julgamento pela sociedade. Nesse sentido, o não envio de imagens pode ser uma forma de autopreservação, em especial perante a comunidade que acessa as páginas.

Em ambos os casos representados pela figura 3, transcritos nos exemplos 1 e 2, e pela figura 4 (B-PaP), transcrita no exemplo 3, há um apelo dirigido tanto à pessoa pretendida, como à comunidade. Tal apelo advém do fato de, dentro do contexto retratado pela postagem, não haver contato direto prévio entre o remetente e a pessoa foco de sua postagem. No caso de MP, o pedido parece se fiar na impossibilidade de localização do rapaz retratado na narrativa, dado o intenso fluxo de usuários do sistema. Já nos contextos de PG e PaP, a presença da imagem e o contexto reduzido fazem com que o foco da paquera seja mais facilmente localizado. No caso da figura 3-A, a nomeação do local permite uma identificação mais precisa, ancorando a solicitação em dados mais concretos do contexto geral. No caso da figura 3-B, o processo de solicitação se ancora em elementos contextuais mais tênues, isso porque o local representado pela fotografia não é nomeado do texto. Naturalmente, os membros da comunidade são capazes de inferir a localização, dadas suas práticas sociais típicas; todavia ela é bem menos transparente para não-participantes.

Contrastivamente, a figura 4 (A e C-PuP) traz exemplos nos quais o apelo é feito de forma direta à pessoa a quem se busca. Em (A), questiona- 
se a não presença; apesar de fazê-lo de forma direta, a continuidade da narrativa coloca a remetente em uma situação assimétrica. Tal assimetria se manifesta na percepção da ausência e das poucas oportunidades de interação existente entre eles, algo que culmina com a expressão do desejo de conhecer "melhor" o rapaz. Apesar de o único elemento modalizante ser o uso do pretérito imperfeito na proposição final (queria) e pelo elemento circunstancial (poucas vezes), o tom melancólico se estabelece também graças à relação atributiva na qual a remetente associa um sentimento de ausência emocional à não presença física. Essa mesma utilização do tempo verbal e essa mesma relação de necessidade em encontrar a pessoa são colocadas figura 3-A e B em diferentes graus. Apesar de querer encontrar o objeto de seu afeto, a postagem da figura 4-A não parece colocar a remetente em um papel subalterno, apesar de solicitar ajuda, como já colocado, há um processo de avaliação que aventa a possibilidade de constituição de um encontro futuro. Isso se dá pela natureza dos termos utilizados por ela (te achei muito crush) que, no contexto do uso brasileiro pode ser desde um elogio à beleza física até a sinalização de abertura para um encontro sexual. Esse fato deixa um grande campo de interpretação por parte do leitor. Já na figura 3-B o processo narrativo cria um tom muito mais próximo da figura 4-A. Apesar de menos melancólico ele possui uma forte avaliação em termos de sentimento (...o amor da minha vidaaaaaa), algo amplamente potencializado pela repetição da vogal final da palavra vida (vidaaaaaa).

Já na figura 4 (C-PuP) o pedido é feito de forma direta ao destinatário do afeto praticamente sem modalização alguma e também sem uma explicitação, mesmo que ambígua, das intenções da remetente. Algo muito parecido, no que tange à lacuna em termos dos objetivos sentimentais, é observado na figura 4 (B-PaP): ali o questionamento também é dirigido diretamente à comunidade. sendo também um dos raros casos no qual nenhuma parte da mensagem é voltada à pessoa pretendida.

\section{CONSIDERAÇÕES FINAIS}

Este artigo teve por objetivo refletir sobre as comunidades Spotted no Facebook a partir de três perspectivas principais, a Linguística Sistêmico-Funcional, a Comunicação Mediada por Computador e a Ciência das Redes. De forma a alcançar tal objetivo, as comunidades foram estudadas a partir de suas conexões com outras páginas dentro da plataforma e da estrutura de suas postagens, em um processo analítico que se serviu tanto da abordagem quantitativas quanto da qualitativa. 
Os resultados mostram que foi possível traçar um perfil geral dos processos de interação nas comunidades em termos de suas métricas de interação. Tal perfil também foi observado a partir da Ciência das Redes, que possibilitou determinar qual perfil de conexão duas das páginas mantêm. Tais conexões parecem refletir como tais comunidades se relacionam não apenas no mundo on-line como também off-line: elas parecem ser um parâmetro identificador do papel dessas comunidades no contexto em que ocorrem.

Em termos da estrutura das postagens, foi possível observar que são utilizados tanto o texto como o texto em sua relação com imagens. Apesar de o perfil funcional ser bem particular em cada uma postagem, foi possível concluir que a exteriorização de sentimentos e a auto(identificação) de pessoas pretendidas foi o foco principal. A utilização ou não de imagens na postagem, todavia, parece estar condicionada às políticas de privacidade impostas em cada uma das comunidades, que possuem mecanismos próprios para intermediar o contato entre pretendentes.

Do ponto de vista da linguagem dos posts, os resultados parecem indicar que, em linhas gerais:

- Campo: a definição de paquera é dependente de elementos contextuais. Entre eles estariam o local onde a pessoa foi avistada, e os possíveis eventos em que participa.

- Modo: a modo escrito é predominante, mas o visual ocorre por meio de fotografias que buscam ou identificar a pessoa objeto de desejo ou ilustrar sentimentos. A identificação pode ou estar ancorada em uma relação entre a linguagem verbal e a visual ou simplesmente utilizando elementos de visualidade, tais como marcação na fotografia. Imagens ilustrativas são de caráter subjetivo.

- Relações: a pessoa que realiza a paquera não se identifica ao passo que a paquera o é. Isso garante o anonimato de quem procura o parceiro, mas também a coloca em uma situação de desvantagem, uma vez que ela jamais pode ser respondida.

Ressalta-se que as comunidades dessa natureza são um fenômeno bastante comum no contexto do brasileiro, havendo, pelo menos, uma comunidade em cada universidade — por vezes mais de uma —, além de diversos dedicados a espaços urbanos variados - como é o caso 
do metrô paulistano. Logo, é importante compreender como os jovens utilizam esses espaços de socialização em suas relações contemporâneas. Apesar das contribuições realizadas neste artigo, acredito que muito ainda pode ser discutido, ampliando seus resultados e analisando novas comunidades.

\section{AGRADECIMENTOS}

Gostaria de agradecer à FAPESP, processo n 2016/11230-5, pelo apoio financeiro a esta pesquisa.

\section{REFERÊNCIAS}

ARORA, Payal; SCHEIBER, Laura. Slumdog Romance: Facebook Love and Digital Privacy at the Margins. Media, Culture \& Society, v. 39, n. 3, p. 408-422, 2017.

BARABÁSI, Albert-László. Linked. Cambridge: Perseus Pub, 2002.

BREZINA, Vaclav. Statistics in corpus linguistics. Cambridge; New York: Cambridge University Press, 2018.

CORREA, Teresa; HINSLEY, Amber Willard; DE ZÚÑIGA, Homero Gil. Who Interacts on the Web?: The Intersection of Users' Personality and Social Media Use. Computers in Human Behavior, v. 26, n. 2, p. 247-253, 2010.

EGGINS, Suzanne. An introduction to systemic functional grammar. London: Printer Publishers, 1994.

ELLISON, Nicole B.; STEINFIELD, Charles; LAMPE, Cliff. The Benefits of Facebook "Friends:" Social Capital and College Students' Use of Online Social Network Sites. Journal of Computer-Mediated Communication, v. 12, n. 4, p. 1143-1168, 2007.

FOX, Jesse; WARBER, Katie M. Romantic Relationship Development in the Age of Facebook: An Exploratory Study of Emerging Adults' Perceptions, Motives, and Behaviors. Cyberpsychology, Behavior, and Social Networking, v. 16, n. 1, p. 3-7, 2013.

GABARDO, Maristella; LIMA-LOPES, Rodrigo Esteves de. Ni una menos: ciência das redes e análise de um coletivo feminista. Humanidades \& Inovação, v. 5, n. 3, p. 44-58, 2018.

HALLIDAY, M. A. K. An introduction to functional grammar. London: Arnold, 1994.

HALLIDAY, M. A. K.; HASAN, R. Language, context and text. 3. impr ed. Oxford: Oxford Univ. Press, 1991.

HALLIDAY, M.A.K. Language as social semiotic: the social interpretation of language and meaning. London: University Park Press, 1978.

HERRING, S. C. Computer-mediated Discourse. In: SCHIFFRIN, D.; TANNEN, D.; 
HAMILTON, Heidi Ehernberger (Org.). The handbook of discourse analysis. Blackwell handbooks in linguistics. Malden: Blackwell Publishers, 2001. p. 612-634.

Piso conversacional e gênero na CMC. In: SHEPHERD, Tania G; SALIÉS, Tânia G (Org.). Linguística da Internet. São Paulo: Editora Contexto, 2013. p. 95-124.

IEDEMA, R. Multimodality, resemiotization: extending the analysis of discourse as multisemiotic practice. Visual Communication, v. 2, n. 1, p. 29-57, 2003.

KRESS, G. Against Arbitrariness: The Social Production of the Sign as a Foundational Issue in Critical Discourse Analysis. Discourse \& Society, v. 4, n. 2, p. 169-191, 1993.

Multimodality. London: Routledge, 2010.

LIMA-LOPES, R. E. Análise de registro e ciência das redes estudando um grupo de whatsapp dedicado à produção de cerveja artesanal. Hipertextus Revista Digital, v. 16, p. 134-161, 2017.

Apontamentos sobre mídias digitais: qual caminho para o Gênero 2.0? In: LIMALOPES, Rodrigo Esteves de; BUZATO, Marcelo El Khouri (Org.) Gênero Reloading. Campinas: Pontes, 2018.

LIMA-LOPES, R. E.; PIMENTA, I. \#Mulheresnofutebol: transitividade e avaliatividade na identificação de padrões sexistas. Humanidades \& Inovação, v. 4, n. 6, p. 116-132, 2017.

MARTIN, J.R. Meaning matters: a short history of systemic functional linguistics. Word, v. 62, n. 1, p. 35-58, 2016.

OAKES, M. P. Statistics for corpus linguistics. Edinburgh: Edinburgh University Press, 1998.

OROSZ, G. et al. Elevated romantic love and jealousy if relationship status is declared on Facebook. Frontiers in Psychology, v. 6, p. 1-6, 2015.

PAPP, L. M.; DANIELEWICZ, J.; CAYEMBERG, C. "AreWe Facebook Official?" Implications of Dating Partners' Facebook Use and Profiles for Intimate Relationship Satisfaction. Cyberpsychology, Behavior, and Social Networking, v. 15, n. 2, p. 85-90, 2012.

ROGERS, R. Digital Methods initiative. [s.d.]. Disponível em: https://wiki.digitalmethods. net/Dmi/ToolDatabase. Acesso em: 30 mar. 2020.

ROCHADIAT, A.; TONG, S. Tom; NOVAK, J. M. Online Dating and Courtship among Muslim American Women: Negotiating Technology, Religious Identity, and Culture. New Media \& Society, v. 20, n. 4, p. 1618-1639, 2018.

ROSS, Craig et al. Personality and motivations associated with Facebook use. Computers in Human Behavior, v. 25, n. 2, p. 578-586, 2009. 
SCHNEBLE, C. O.; ELGER, B. S.; SHAW, D. The Cambridge Analytica affair and Internetmediated research. EMBO reports, v. 19, n. 8. DOI 10.15252/embr.201846579.

SCOTT, J. What Is Social Network Analysis? London; New York: Bloomsbury Academic, 2013.

SMITH, A.; DUGGAN, M. Online Dating \& Relationships. Pew Research Center: Internet, Science \& Tech. Disponível em: <http://www.pewinternet.org/2013/10/21/ online-dating-relationships/>. Acesso em: 27 jul. 2018, 2013

SPRECHER, S. Relationship Initiation and Formation on the Internet. Marriage \& Family Review, v. 45, n. 6-8, p. 761-782, 2009.

VIAN JR, O.; LIMA-LOPES, R. E. A perspectiva teleológica de Martin para a análise dos gêneros textuais. In: MEURER, José; MOTTA-ROTH, Désirée; BONINI, Adair (Org.) Gêneros: teorias, métodos, debates. Campinas: Parábola, 2005.

WATTS, D. J. The "New" Science of Networks. Annual Review of Sociology, v. 30, n. 1, p. 243-270, 2004.

ZELL, A. L.; MOELLER, L. Are You Happy for Me on Facebook? The Potential Importance of "Likes" and Comments. Computers in Human Behavior, v. 78, p. 26-33, 2018.

Recebido em: 16/07/2020

Aceite em: 26/11/2020 